\title{
UJI KETERKAITAN TINGKAT PENERAPAN PHT TANAMAN PADI (Oryza Sativa L) TERHADAP FAKTOR SOSIAL PETANI (STUDI KASUS DI DUSUN BANJARDOWO KECAMAT AN JOMBANG)
}

\author{
Isnani Khumairoh ${ }^{1}$, Ambar Susanti ${ }^{2}$, Canggih Nailil Maghfiroh ${ }^{3}$ \\ ${ }^{1}$ Program Studi Agribisnis, Universitas KH. A. Wahab Hasbullah \\ ${ }^{2}$ Program Studi Agroekoteknologi, Universitas KH. A. Wahab Hasbullah \\ ${ }^{3}$ Program Studi Rekayasa Pertanian dan Biosistem, Universitas KH. A. Wahab \\ Hasbullah \\ 1Email: Isnanikhumairoh17@gmail.com
}

\begin{abstract}
There are age, education level, and duration of farmers in cultivating rice, are social factors that need to be studied to determine the extent to which these factors affect the implementation of IPM on farmers. This study aims to determine the relationship between social factors of farmers with the level of application of integrated pest control technology (IPM) in Dsn. Banjardowo district. Jombang. The research method used is descriptive analysis method, with a variable consisting of 2 variables, namely the $X$ variable which consists of age, education and duration of farming, and $2 Y$ variables which consist of the application of IPM. The research population amounted to 112 respondents with a sample of 20 respondents. The questionnaire data collection technique (questionnaire) was used as a measurement with an ordinal scale or score. The factors of age, education level and duration of farming are significantly related to the level of implementation of Integrated Pest Management (IPM) in Banjardowo Hamlet, Banjardowo Village, Jombang District.
\end{abstract}

Keywords: Social factors, Implementation IPM, Paddy cultivate

\begin{abstract}
ABSTRAK
Faktor social yaitu umur, tingkat pendidikan, dan lamanya petani dalam melakukan budidaya tanaman padi, menjadi factor yang perlu dikaji untuk mengetahui sejauh mana factor tersebut berpengaruh terhadap penerapan PHT pada petani. Penelitian ini bertujuan untuk mengetahui keterkaitan faktor sosial petani dengan tingkat penerapan teknologi pengendalian hama terpadu (PHT) di Dsn. Banjardowo Kec. Jombang. Metode penelitian yang digunakan yaitu metode analisa deskriptif, dengan variabel yang terdiri dari 2 variabel yaitu variabel $X$ yang terdiri dari umur, pendidikan dan lamanya usahatani, dan 2 variabel $Y$ yang terdiri dari penerapan PHT. Populasi penelitian berjumlah 112 responden dengan sampel 20 responden. Teknik pengumpulan data kuesioner (angket) digunakan sebagai pengukuran dengan skala ordinal atau skor. Faktor umur, tingkat pendidikan dan lamanya usaha tani berketerkaitan nyata dengan tingkat penerapan Pengendalian Hama Terpadu (PHT) di Dusun Banjardowo, Desa Banjardowo Kecamatan Jombang.
\end{abstract}

Kata Kunci: Faktor sosial, Penerapan PHT, Tanaman padi 


\section{PENDAHULUAN}

Desa Banjardowo termasuk dalam wilayah kecamatan Jombang. Berdasarkan data Badan Pusat Statistik, rata - rata produksi padi di desa tersebut di tahun 2018 berkisar 66,4 kw/Ha, hanya mengalami peningkatan 0,3 kw/Ha dengan produksi pada tahun 2017 yang berkisar 66,1 kw/Ha. Dusun Banjardowo merupakan bagian dari Desa Banjardowo, yang merupakan salah satu penghasil beras di Kabupaten Jombang. Berdasarkan data Rencana Definitif Kebutuhan Kelompok (RDKK) tahun 2021, dusun tersebut mempunyai luas lahan untuk penanaman padi sekitar 458.31 hektar. Oleh karena itu perlu ditingkatkan produksi padi secara optimal, mengingat Desa Banjardowo hanya mengalami penambahan $0,3 \mathrm{kw} / \mathrm{Ha}$. Organisme Pengganggu Tanaman (OPT) menjadi kendala dalam upaya peningkatan produksi padi, diantaranya adalah hama. Penggerek batang padi kuning menjadi alah satu hama yang sering dijumpai pada ekosistem sawah sepanjang tahun di Dusun Banjardowo ialah (Aryantini dkk, 2015 dalam Sudewi.S,dkk, 2020 ).

Umumnya petani mengandalkan pestisida sebagai bahan untuk pengendalian hama dan penyakit yang diketahui tidak dianjurkan untuk dipakai secara terus menerus. Hal ini berketerkaitan dengan perubahan spesies, resistensi OPT, resurjensi, dan pencemaran lingkungan (Widyaningsih, 2014 dalam Fitriani 2016). Kesadaran masyarakat diperlukan terhadap pentingnya pengendalian yang tepat pada lingkungan hidup dalam budidaya pertanian . Permasalahan di atas semakin mendorong penerapan dan pengembangan Pengendalian Hama Terpadu (PHT) sebagai usaha untuk menekan penggunaan pestisida sebagai satu - satunya teknik untuk mengendalikan OPT. Adapun salah satu tujuan penerapan pengendalian hama terpadu ialah untuk melestarikan lingkungan dengan cara memantapkan hasil produksi untuk menciptakan kesejahteraan petani (Susanti 2018).

Akan tetapi petani masih banyak yang belum menerapkan inovasi,dibutuhkan rentang waktu yang cukup lama agar mampu diterima dan diterapkan sebagai bagian keperluan petani (Anugrah dan Wardana, 2008).Penyampaian informasi tentang penerapan PHT ditujukan kepada petani dalam budidaya tanaman padi. Hal ini dilakukan untuk menyadarkan petani akan pentingnya penerapan pengendalian hama terpadu (PHT). Terdapat beberapa factor yang berpengaruh dalam penerapan PHT, yang mempengaruhi petani dalam menerima informasi tersebut. Faktor social seperti umur, tingkat pendidikan, dan lamanya petani dalam melakukan budidaya tanaman padi, menjadi factor yang perlu dikaji. Pengkajian ini untuk mengetahui sejauh mana factor tersebut berpengaruh terhadap penerapan PHT pada petani.

Oleh karena itu dilaksanakan riset tentang keterkaitan faktor sosial petani terhadap tingkat Penerapan Teknik PHT pada tanaman Padi di Dusun Banjardowo Kec. Jombang. Hal di atas bertujuan untuk mengetahui keterkaitan factor social petani terhadap tingkat penerapan PHT tanaman padi di Dusun Banjardowo, Kecamatan Jombang.

\section{METODE PENELITIAN}

Penelitian dilaksanakan di Dusun Banjardowo Kecamatan Jombang dan laboratorium program studi Agribisnis Fakultas Pertanian Universitas KH.A. Wahab Hasbullah. dengan pertimbangan bahwa Dusun Banjardowo menjadi tempat penelitian karena mempunyai mayoritas penduduk sebagai petani dengan rata-rata memiliki luas lahan $6 \mathrm{Ha}$. Penelitian ini dilaksanakan pada bulan Maret sampai Mei 2021. 
Pada penelitian ini digunakan metode dasar deskriptif dan korelasi. Dua puluh responden diambil dengan metode purpose random sampling dari populasi seluruh petani di Dusun Banjardowo yang berjumlah 112 responden. Data primer dihasilkan dari responden melalui alat bantu kuesioner. Dua variabel digunakan pada penelitian ini, variable pertama yaitu variabel $X$ yang terdiri Umur (X1), Pendidikan (X2), dan lamanya usahatani (X3). Variabel ke dua adalah variabel $Y$ yaitu tingkat penerapan pengelolaan hama terpadu tanaman padi.

Untuk menganalisa variabel faktor sosial, diukur dengan alat ukur kuesioner dengan menggunakan skala ordinal yaitu jawaban responden yang terdiri tiga kategori yaitu tinggi (skor 3), sedang (skor 2) dan rendah (skor 1).

Tabel 1.

Deskripsi Skoring berdasarkan Kriteria untuk Variabel Faktor Sosial (X)

\begin{tabular}{llll}
\hline Variabel (X) & Indikator & Kriteria & Skor \\
\hline Usia & & Rendah: $<40$ tahun & 1 \\
& & Sedang : 40-60 & 2 \\
& & tahun & 3 \\
& & Tinggi : $>60$ tahun & \\
\hline Pendidikan & & Rendah: $\leq$ SD & 1 \\
& & Sedang : SMP-SMA & 2 \\
& & Tinggi: $>$ SMA & 3 \\
\hline Rentang waktu & Lamanya petani & Rendah: $<10$ tahun & 1 \\
usaha tani & melakukan budidaya & Sedang: 10-20 tahun & 2 \\
& tanaman padi & Tinggi: $>20$ tahun & 3 \\
\hline
\end{tabular}

Sumber: Sugiyono, $2016 a$

Untuk mengetahui adanya keterkaitan antara faktor sosial petani dengan tingkat penerapan PHT digunakan uji korelasi Rank Spearman (RS).

Rumus dari korelasi rank spearman $\left(r_{s}\right)$ dapat dilihat pada uraian dibawah ini:

$$
\begin{aligned}
& r_{s}=\frac{6 \sum d i^{2}}{n\left(n^{2}-1\right)} \\
& \text { Keterangan : } \\
& r_{s}=\text { Koefisien Korelasi Rank Spearmen } \\
& N=\text { Banyaknya sampel } \\
& d i=\text { Selisih antar ranking dari variabel }
\end{aligned}
$$

Dengan penilaian: arah keterkaitan Negatif: apabila nilai $X$ bertambah maka nilai $Y$ berkurang dan sebaliknya, dan Positif: apabila nilai $X$ bertambah maka nilai $Y$ bertambah dan sebaliknya(Sa'adah, 2017).

Tabel 2

Interpretasi Nilai Rho

\begin{tabular}{ll}
\hline Range Besaran Nilai $\boldsymbol{r}$ & Interpretasi \\
\hline $0.800 \mathrm{~s} / \mathrm{d} 1.00$ & Tinggi \\
\hline $0.600 \mathrm{~s} / \mathrm{d} 0.800$ & Cukup \\
\hline $0.400 \mathrm{~s} / \mathrm{d} 0.600$ & Agak rendah \\
\hline $0.200 \mathrm{~s} / \mathrm{d} 0.400$ & Rendah \\
\hline $0.000 \mathrm{~s} / \mathrm{d} 0.200$ & Sangat rendah \\
\hline
\end{tabular}

Sumber: Sugiyono, (2016b) 
UJi t student digunakan untuk menguji tingkat signifikasi $r_{s}$. Hal ini digunakan apabila sampel yang diambil lebih dari 10 (Siegel, 1994 dalam Maris, 2013) dengan rumus sebagai berikut:

$$
t=r_{s} \sqrt{\frac{N-2}{1-r_{s}^{2}}}
$$

Dimana:

$\mathrm{N}=$ jumlah sampel

rs = koefisien korelasi Rank Spearmean

Kriteria pengambilan keputusan:

1. Apabila t hitung $\geq t$ tabel $(\alpha=0,05)$ maka $H_{0}$ ditolak, berarti terdapat pengaruh yang nyata antara faktor sosial dengan tingkat penerapan Pengelolaan Hama Terpadu (PHT) di Dusun Sumberwinong, Kecamatan Jombang.

2. Apabila $t$ hitung $<t$ tabel $(\alpha=0,05)$ maka $H_{0}$ diterima, berarti tidak terdapat pengaruh yang nyata antara faktor sosial dengan tingkat penerapan Pengelolaan Hama Terpadu (PHT) di Dusun Banjardowo, Kecamatan Jombang.

\section{HASIL DAN PEMBAHASAN}

\section{Umur}

Umur petani di Dusun Banjardowo Kec. Jombang rata-rata berkisar antara 30-70 tahun. Umur menjadi factor yang berpengaruh terhadap perilaku petani untuk mengambil keputusan dalam menerapkan adopsi inovasi pada pengelolaan lahan (Wangke \& Suzana , 2016 dalam Novanda, 2020). Berikut Tabel 3 yang menunjukkan persentase umur petani responden

Tabel 3

Distribusi responden berdasarkan umur

\begin{tabular}{lllcc}
\hline No. & Umur (Tahun) & Kategori & Jumlah (Orang) & Presentase(\%) \\
\hline 1. & $<40$ Tahun & Rendah & 4 & $20 \%$ \\
2. & $40-60$ Tahun & Sedang & 5 & $25 \%$ \\
3. & $>60$ Tahun & Tinggi & 11 & $55 \%$ \\
\hline & Jumlah & & 20 & $100 \%$
\end{tabular}

\section{Sumber : Data primer diolah, 2021}

Tabel 3 menunjukkan mayoritas umur petani responden di Dsn. Banjardowo berada pada kategori tinggi, yaitu 11 responden berumur $>60$ tahun atau berkisar $55 \%$. Lima responden dalam kategori sedang, yaitu berumur antara 40-60 Tahun. Pada kategori terendah yaitu umur < 40 tahun berjumlah 4 petani responden. Hal ini menunjukkan bahwa petani dengan umur $>60$ tahun paling besar dalam melakukan budidaya pertanian tanaman padi. Petani dengan rentang usia 40 - 60 tahun mampu bekerja dengan fisik yang lebih kuat untuk menyerap informasi dan inovasi sehingga lebih mudah dalam mengpenerapankan PHT pada tanaman padi. Akan tetapi pada rentang umur 
tersebut, hanya terdapat $25 \%$. Sedangkan pada rentang $<40$ tahun hanya berkisar $20 \%$.

\section{Pendidikan}

Pendidikan dalam hal ini adalah dimana responden mengeyam pendidikan terakhir yang pernah ditamatkannya. Tingkat pendidikan petani berpengaruh terhadap kemampuannya melakukan budidaya tanaman . pengetahuan dan informasi yang didapatkan petani semakin banyak apabila tingkat pendidikan yang ditempuh semakin tinggi(Burhansyah, 2016).

Tabel 4

Distribusi responden berdasarkan tingkat pendidikan

\begin{tabular}{lllcc}
\hline No. & $\begin{array}{l}\text { Tingkat } \\
\text { Pendidikan }\end{array}$ & Kategori & $\begin{array}{l}\text { Jumlah } \\
\text { (Orang) }\end{array}$ & Presentase(\%) \\
\hline 1. & SSD & Rendah & 4 & $20 \%$ \\
2. & SMP-SMA & Sedang & 11 & $55 \%$ \\
3. & >SMA & Tinggi & 5 & $25 \%$ \\
\hline & Jumlah & & 20 & $100 \%$ \\
\hline
\end{tabular}

Sumber data: Data primer diolah, 2021

Tabel 4 menampilkan mayoritas responden terbanyak berada pada kategori sedang, yaitu pada tingkat pendidikan SMP - SMA sebanyak 11 responden dengan presentase $55 \%$. Hal ini juga mengindikasikan bahwa masyarakat mulai memperhatikan pendidikan. Sebanyak 5 responden berada pada kategori tinggi yakni berada pada tingkat pendidikan tinggi atau >SMA dengan presentase $25 \%$. Responden dengan katagori rendah berada pada tingkat pendidikan SD sebanyak 4 responden dengan jumlah presentasi paling kecil diantara yang lainnya yaitu $20 \%$. Hal ini disebabkan petani tidak mempunyai cukup dana melanjutkan pendidikan ke tingkat lebih tinggi. Mayoritas responden dengan tingkat pendidikan rendah ialah mereka yang usianya $>60$ tahun.

\section{Lamanya Usahatani}

Lamanya usaha tani dalam penelitian ini merupakan pengalaman petani dalam budidaya tanaman padi yang dijadikan sebagai pengetahuan dan pembelajaran dalam mengendalikan hama dan penyakit dimasa yang akan datang. Hal tersebut dapat dijadikan sebagai pembelajaran dalam mengatasi permasalahannya agar terhindar dari resiko kegagalan akibat serangan hama. Tabel 5 menampilkan distribusi responden berdasarkan lamanya usaha tani.

Tabel 5

Distribusi responden berdasarkan lamanya usahatani

\begin{tabular}{lllcc}
\hline No. & $\begin{array}{l}\text { Lamanya } \\
\text { Usahatani }\end{array}$ & Kategori & Jumlah (Orang) & Presentase(\%) \\
\hline 1. & $<10$ Tahun & Rendah & 5 & $25 \%$ \\
2. & 10-20 Tahun & Sedang & 8 & $40 \%$ \\
3. & $>20$ Tahun & Tinggi & 7 & $35 \%$ \\
\hline & Jumlah & & 20 & $100 \%$
\end{tabular}

Sumber :Data primer diolah, 2021 
Tabel 5 menampilkan 7 responden di kategori tinggi dengan lama berusaha tani $>20$ tahun dengan presentase $35 \%$. 8 responden berada pada kategori sedang dengan lama berusaha tani $10-20$ tahun dengan presentase $40 \%$. Responden dengan pengalaman berusaha tani $10-20$ tahun rata-rata melakukan kegiatan berusaha tani karena merupakan kegiatan turun temurun.5 responden berada pada kategori rendah dengan lama beusaha tani $<20$ tahun dengan presentase $25 \%$. Hal ini dikarenakan banyak remaja yang baru memulai berusaha tani namun kemudian memilih untuk tidak meneruskannya.

\section{Tingkat Penerapan Petani Terhadap PHT Tanaman Padi}

Tingkat penerapan petani terhadap PHT padi merupakan suatu penerapan dalam berusaha tani yang dilakukan oleh petani dengan berbagai inovasi untuk mendukung transformasi yang lebih baik. Adapun hasil distribusi tingkat penerapan PHT padi diperoleh pada Tabel 6 .

Tabel 6

Distribusi responden berdasarkan tingkat penerapan PHT

\begin{tabular}{|c|c|c|c|c|c|}
\hline & & & \multicolumn{3}{|c|}{ Jumlah Responden } \\
\hline No & $\begin{array}{c}\text { Tingkat } \\
\text { Penerapan }\end{array}$ & Indikator & $\begin{array}{l}\text { Kategori } \\
\text { rendah }\end{array}$ & $\begin{array}{l}\text { Kategori } \\
\text { Sedang }\end{array}$ & $\begin{array}{l}\text { Kategori } \\
\text { Tinggi }\end{array}$ \\
\hline 1 & $\begin{array}{l}\text { Pengelolaan } \\
\text { Lahan }\end{array}$ & $\begin{array}{l}\text { Pemberoan } \\
\text { Lahan }\end{array}$ & 4 & 5 & 11 \\
\hline 2 & Pembibitan & Perlakuan benih & 1 & 8 & 11 \\
\hline 3 & Penanaman & $\begin{array}{l}\text { Pergiliran } \\
\text { tanaman }\end{array}$ & 2 & 10 & 8 \\
\hline 4 & Pemupukan & Jenis pupuk & 4 & 11 & 5 \\
\hline 5 & PHT & $\begin{array}{l}\text { PHT dan Musuh } \\
\text { alami }\end{array}$ & - & 13 & 7 \\
\hline 6 & $\begin{array}{l}\text { Pengamatan } \\
\text { OPT dan } \\
\text { Musuh Alami }\end{array}$ & $\begin{array}{l}\text { Perkembangan } \\
\text { OPT dan Musuh } \\
\text { alami }\end{array}$ & 5 & 8 & 7 \\
\hline
\end{tabular}

Sumber: Data primer diolah, 2021

Tabel 6 menampilkan bahwa responden umumnya melakukan pengelolahaan lahan dengan baik, sedangkan responden yang kurang memahami tentang pengelolaan lahan berjumlah sedikit. Pemberoan bertujuan untuk mengosongkan lahan agar mengurangi ketersediaan makanan hama pada lahan tersebut (Untung, 2006). Adanya teknik pemberoan diharapkan dapat menurunkan populasi hama, karena teknik tersebut mengganggu siklus hidup hama.

Menurut Kuswanto (1997, dalam Maulana,dkk. 2017), varietas bermutu dan unggul digunakan untuk menunjang produksi dan produktivitas tanaman padi. Oleh karena itu umumnya petani sudah mengetahui varietas padi yang tahan terhadap serangan hama tanaman padi. Petani selalu melakukan pembibitan dan penanaman serentak yang dilakukan paling lambat 15 hari untuk menyelesaikan penanaman dengan sistem gilir tanpa upah. Hanya sebagian kecil saja petani yang melakukan pembibitan dan penanaman mandiri. Petani yang melakukannya secara mandiri ialah mereka yang tidak menerapkan sistem gilir tanpa upah.

Petani juga menerapkan pemupukan berimbang sesuai dosis yang dianjurkan oleh petugas penyuluhan dan hanya sebagian kecil saja yang tidak melakukan pemupukan sesuai dosis, hal ini karena mereka kurang memahami 
pentingnya pemupukan berimbang bagi tanaman. Selain itu, pemupukan berimbang dalam hal ini adalah pemberian antara pupuk anorganik dengan organic. Adanya ketergantungan petani terhadap pupuk anorganik, berdampak pada aplikasi pupuk kimia sintetik yang berlebihan, sehingga dapat menimbulkan berbagai masalah apabila digunakan secara kontinyu dan dalam jangka waktu lama (Susanti, dkk. 2020). Lebih lanjut Susanti,dkk (2020) menyatakan bahwa permasalahan tersebut diantaranya degradasi kesuburan tanah, terjadi keracunan akibat senyawa kimia sintetik yang terkandung dalam pupuk anorganik, berakibat pada kehidupan mikroorganisme berguna dalam tanah berkurang dan mengalami penurunan populasi dalam tanah.

Tahapan selanjutnya yang biasa dilakukan petani setelah melakukan pemupukan ialah melakukan pengelolaan hama pada tanaman padi. Rata - rata seluruh petani melakukan pengendalian hama dengan melihat keadaan tanaman sebelum melakukan pengendalian maupun pemberantasan hama. Petani juga melakukan pengamatan hama dan musuh alami secara berkala tetapi tidak terjadwal, beberapa petani melakukan pengamatan seminggu sekali namun ada juga yang melakukan pengamatan setiap harinya. Biasanya petani yang melakukan pengamatan setiap hari ialah mereka yang pekerjaan utamanya ialah bertani. Untung (2006) menyatakan bahwa pemantauan perlu dilaksanakan untuk mengetahui perkembangan populasi hama, musuh alami, dan keadaan tanaman budidaya, serta lingkungan. Hasil pemantauan dapat digunakan untuk mengambil keputusan yang diperlukan untuk tindakan pengendalian hama.

Umumnya secara alami, musuh alami mampu mengendalikan hama apabila factor lingkungan mendukung perkembangan musuh alaminya (Moningka, dkk. 2012), karena berperan penting dalam menekan populasi hama sampai pada aras yang tidak menimbulkan kerugian(Heviyanti dan Cut Mulyani, 2016). Pengelolaan tanaman secara terpadu mampu mengendalikan populasi serangga dan mempertahankan populasi musuh alami dan serangga netral tetap tinggi dari fase vegetatif awal sampai bera (Macfadyen et al., 2015, dalam Sumini dan Samsul Bahri, 2020).

\section{Hasil Analisis Uji keterkaitan Rank Spearman}

Uji korelasi Rank Spearman $\left(r_{s}\right)$ dipakai untuk mengetahui keterkaitan faktor sosial terhadap penerapan PHT digunakan. Besaran nilai thitung dan tabel. Digunakan untuk menguji tingkat signifikansi terhadap nilai yang diperoleh. Hasil analisa keterkaitan antar faktor sosial dengan tingkat penerapan dapat ditunjukkan di Tabel 7.

Tabel 7

Keterkaitan Umur terhadap Penerapan PHT

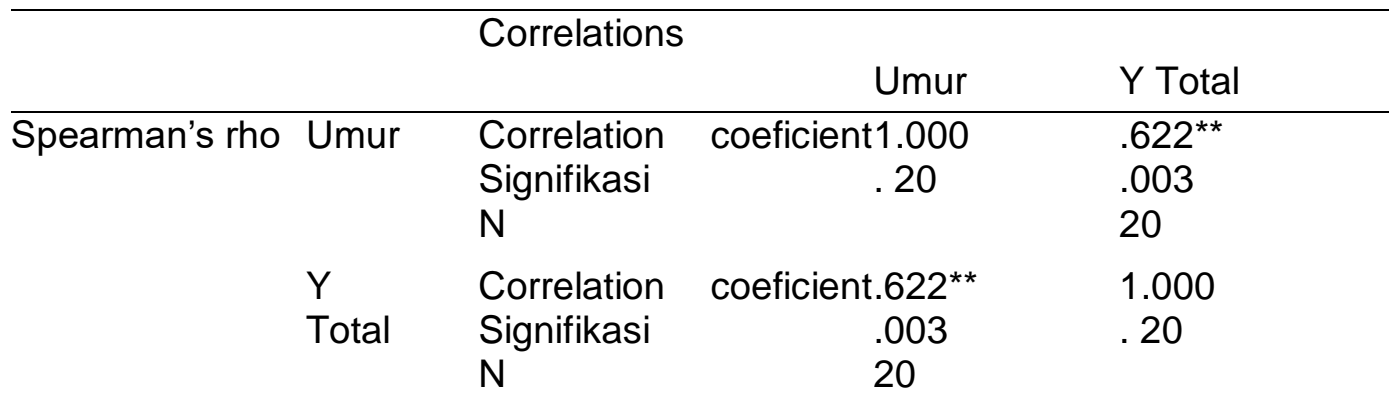

Sumber data: Data primer diolah, 2021 
Pada Tabel 7 menampilkan adanya keterkaitan yang cukup antara umur dengan tingkat penerapan PHT dengan arah keterkaitan yang positif. Hal ini dapat diketahui dengan melihat perolehan angka koefisien korelasi sebesar $.622^{* *}$. Korelasi bernilai signifikan karena 0,000 lebih kecil dari 0,01 serta kedua variable bernilai positif (searah). karena umur dijadikan sebagai tolak ukur keberhasilan petani dalam berusaha tani yang berpengaruh pada kinerja dan inovasi dalam mengelola lahannya. Pratiwi dan Sudrajat (2012) mengungkapkan umur petani yang semakin tua diasumsikan akan mempunyai kemampuan kinerja dan inovasi dalam mengelola lahan semakin rendah dibanding petani yang masih berusia lebih muda mereka cenderung lebih muda dalam menerima inovasi dan tingkat kinerja yang mereka miliki lebih tinggi.

Keterkaitan antara tingkat pendidikan petani dengan tingkat penerapan PHT ditunjukkan pada tabel 8 di bawah ini.

Tabel 8

Keterkaitan pendidikan dengan penerapan $\mathrm{PHT}$ tanaman padi

\begin{tabular}{|c|c|c|c|c|}
\hline & & elations & & \\
\hline & & & Pendidikan & Y Total \\
\hline Spearman & Pendidikan & Correlation & 1.000 & $.460^{*}$ \\
\hline 's rho & & Coeficient & & .041 \\
\hline & & Signifikasi & & 20 \\
\hline & & $\mathrm{N}$ & 2 & \\
\hline & & & 0 & \\
\hline & Y Total & Correlation & $.460^{*}$ & 1.000 \\
\hline & & coeficient & .041 & \\
\hline & & Signifikasi & 20 & 20 \\
\hline & & $\mathrm{N}$ & & \\
\hline
\end{tabular}

Sumber: Data primer diolah, 2021

Pada tabel 8. menunjukkan adanya keterkaitan yang agak rendah antara pendidikan dengan tingkat penerapan PHT tanaman padi dikarenakan nilai signifikan 0,000 lebih kecil dari 0,05 dan berketerkaitan kuat serta searah dengan perolehan nilai koefisien .460* dan angka koefisien bernilai positif. Hal ini berarti pendidikan merupakan faktor penting yang keterkaitannya signifikan terhadap tingkat penerapan PHT karena dalam mengadopsi teknologi PHT, semakin tinggi tingkat pendidikan petani semakin tinggi pula adopsi atau keterampilan dalam menerapkan penerapan PHT. Simanjuntak et al. (2012) menyatakan bahwa pendidikan berpengaruh terhadap kemajuan usaha tani, karena dengan pendidikan petani mampu menelaah dan memahami setiap wawasan yang berkaitan dengan adopsi inovasi perkembangan pertanian.

Tabel 9 menampilkan keterkaitan antara lamanya usahatani dengan tingkat penerapan $\mathrm{PHT}$

Tabel 9

Keterkaitan lamanya berusaha tani dengan tingkat penerapan PHT

\begin{tabular}{lcrrr}
\hline & Correlations & Umur & \multicolumn{1}{c}{ Y Total } \\
\hline Spearman' & Umur & Correlation coeficient & 1.000 & $.694^{\star *}$ \\
s rho & Signifikasi &. & .001 \\
& & N & 20 & 20
\end{tabular}




$\begin{array}{lcrr}\text { Y } & \text { Correlation coeficient } & .694^{* *} & 1.000 \\ \text { Total } & \text { Signifikasi } & .001 & \text {. } \\ & \mathrm{N} & 20 & 20\end{array}$

Sumber data: Data primer diolah, 2021

Pada tabel 9. menunjukan adanya keterkaitan yang cukup antara lamanya usaha tani dengan tingkat penerapan PHT. Hal ini dapat dibuktikan dengan perolehan nilai koefisien $.694^{* *}$ signifikan pada 0,01 level (2-tailed) yang berarti 0,000 lebih kecil dari 0,01 atau memiliki tingkat kesalahan sebesar $1 \%$. Keterkaitan antara lamanya usahatani dengan tingkat penerapan juga dapat dibuktikan bahwa mayoritas petani di Dusun Banjardowo dengan lama berusaha tani $>20$ tahun memiliki pemahaman yang lebih baik dalam mengelola lahan daripada petani yang memiliki pengalaman $<20$ tahun. Elinur et al., (2010) menyatakan bahwa petani dengan tingkat lamanya berusaha tani lebih dari $>20$ tahun berpotensi memiliki keberhasilan dalam berusaha tani meskipun jenjang pendidikan yang mereka tempuh masih tergolong rendah. Akan tetapi, dengan lamanya berusaha tani yang cukup lama mereka sudah terbiasa menghadapi permasalahan yang ada dengan menemukan solusi untuk permasalahannya.

\section{SIMPULAN}

Berdasarkan hasil dan pembahasan diatas, dapat disimpulkan bahwa faktor umur, tingkat pendidikan dan lamanya usaha tani berketerkaitan nyata dengan tingkat penerapan Pengendalian Hama Terpadu (PHT) di Dusun Banjardowo, Desa Banjardowo Kecamatan Jombang. Perlu ditingkatkan pemahaman petani tentang pentingnya pengendalian hama dan penyakit terpadu dengan diadakannya penyuluhan dan pelatihan kepada petani oleh lembaga-lembaga yang terkait.

\section{DAFTAR PUSTAKA}

Anugrah, Iwan Setiajie, and I Putu Wardana. 2008. "Gagasan Dan Penerapan System Of Rice Intensification ( Sri ) dalam Kegiatan Budidaya Padi Ekologis ( Bpe ) Halnya dengan Berbagai Inovasi Telah Berkembang dan Dihasilkan Untuk Pertanian . Beberapa Upaya Konkrit Melalui ProgramProgram Pertanian Telah T." Analisis Kebijakan Pertanian 6 (1): 75-99.

Badan Pusat Statistik. (2019). Kabupaten Jombang dalam Angka 2019.Diakses 2 Maret 2020.

Burhansyah, Rusli. 2016. "Faktor-Faktor Yang Mempengaruhi Adopsi Inovasi Pertanian Pada Gapoktan Puap Dan Non Puap Di Kalimantan Barat (Studi Kasus: Kabupaten Pontianak Dan Landak)." Informatika Pertanian 23 (1): 65. https://doi.org/10.21082/ip.v23n1.2014.p65-74.

Elinur, Priyarsono, D. S., Tambunan, M., \& Firdaus, M. (2010). Indonesian Journal of Agricultural Economics ( IJAE ). Indonesian Journal of Agricultural (IJAE), 2, 97-119.

Fitriani. (2016). Keanekaragaman Arthropoda Pada Ekosistem Tanaman Padi Dengan Aplikasi Pestisida Fitriani. Agrovital, 1(1), 6-8. 
Heviyanti,M., dan Cut Mulyani (2016). Keanekaragaman Predator Serangga Hama Pada Tanaman Padi Sawah (Oryzae sativa, L.) di Desa Paya Rahat Kecamatan Banda Mulia, Kabupaten Aceh Tamiang. AGROSAMUDRA, Jurnal Penelitian, 3 (2). Jul - Des 2016

Novanda, R. R. (2020). Pengaruh Kelembagaan, Pembiayaan, dan Kemandirian terhadap Kewirausahaan Petani Padi metode Hazton di Kabupaten Menpawah Kalimantan Barat. Agriecobis : Journal of Agricultural Socioeconomics and Business, 2(2), 67. https://doi.org/10.22219/agriecobis.vol2.no2.67-75

Maris, P. (2013). Keterkaitan Antara Karakteristik Sosial Ekonomi Petani Dengan Tingkat Adopsi Teknologi PHT Pasca SLPHT Padi Di Desa Metuk Kecamatan Mojosongo Kabupaten Boyolali. Skripsi.

Maulana, W., Suharto, dan Wagiyana. (2017). Respon Beberapa Varietas Padi (Oryza Sativa L.) terhadap Serangan Hama Penggerek Batang Padi dan Walang Sangit (Leptocorisa acuta Thubn.). AGROVIGOR 10 (1): 21- 27 (2017)

Moningka, M., Dantje T, dan Jeane K. (2012). Keragaman Jenis Musuh Alami Pada Serangga Hama Padi Sawah Di Kabupaten Minahasa Selatan. Eugenia, 18 (2);89 - 95. Agustus 2012

Pratiwi, E. R., \& Sudrajat. (2012). Perilaku Petani dalam Mengelola Lahan Pertanian di Kawasan Rawan Bencana Longsor. Jurnal Bumi Indonesia, 1(3), 355-362.

Sa'adah Lailatus. (2017). Analisis Data IBM SPSS STATISTICS 24. Fakultas Ekonomi Universitas KH. A. Wahab Hasbullah Jombang.

Simanjuntak, P., Kimia, L., Alam, B., \& Bioteknologi, P. (2012). Pengaruh Faktor Sosial Ekonomi Terhadap Pendapatan Petani Pinang. Agrium, 17(2), 103108.

Sudewi, S., Ala, A., Baharuddin, B., \& BDR, M. F. (2020). Keragaman Organisme Pengganggu Tanaman (OPT) pada Tanaman Padi Varietas Unggul Baru (VUB) dan Varietas Lokal pada Percobaan Semi Lapangan. Agrikultura, 31(1), 15-24. https://doi.org/10.24198/agrikultura.v31i1.25046

Sugiyono. (2016a). Metode Penelitian Kuantitatif,kualitatif, dan R\&D. Alfabeta Bandung.

Sugiyono. (2016b). Statistika untuk penelitian. Alfabeta Bandung

Sumini dan Samsul Bahri.(2020). Keanekaragaman dan Kelimpahan Musuh Alami Ditanaman Padi Berdasarkan Jarak dengan Tanaman Refugia. J. Agrotek Tropika.8, (1): 177 - 184, Januari 2020

Susanti, A. (2018). Manajemen Tanaman Perkebunan Menuju Komoditi Sehat (Zulfikar (ed.); 1st ed.). Fakultas Pertanian Universitas KH. A. Wahab Hasbullah 
Susanti, A., Siti Nur Qomariyah, \& Rohmat Hidayat. (2020) Pemberdayaan Masyarakat Desa Melalui Pelatihan Pemanfaatan Mikoriza Untuk Pupuk Agens Hayati dan Peluang Agribisnis pada Lahan Marjinal Di Kabupaten Jombang. Prosiding Seminar Nasional Penelitian dan Pengabdian Masayarakat, 5(1) (2020), 200-205.

Untung, K. (2006). Pengantar Pengelolaan Hama Terpadu (edisi kedua). Gadjah Mada University Press Yogyakarta. 